\title{
A Formulation, Optimization and Evaluation of Controlled Released Alginate Beads Loaded-Flurbiprofen
}

\section{Abdellatif $\mathrm{AAH}^{\star 1}$, El Hamd MA ${ }^{2}$ and Saleh $\mathrm{KI}^{1}$}

${ }^{1}$ Department of Pharmaceutics and Industrial pharmacy, Faculty of Pharmacy, Al Azhar University, Assuit 71524, Egypt ${ }^{2}$ Department of Analytical Chemistry, Faculty of Pharmacy, Al-Azhar University, Assuit71524, Egypt

\begin{abstract}
While flurbiprofen (FLB) may cause local gastrointestinal problems such as sensation of warming or burning in mouth and stomach, it is recommended to be limited its therapeutic uses or use it as a modified-release preparation for only once daily-use using Calcium-alginate ( $\mathrm{Ca}$-alginate) beads. Ca-alginate beads were prepared by dropping sodiumalginate solution containing FLB into calcium chloride solution. The prepared Ca-alginate beads loaded-FLB were characterized by optical-microscope at different positions. The weight and swelling percent of the beads were measured for freshly and dried prepared beads. The release of the formed beads was studied in different releasing medias. Finally, after optimizing all conditions the formed beads were used to reduce the paw edema as an anti-inflammatory dosage form. The release of FLB from the formed beads in a phosphate buffer $(0.2 \mathrm{M}, \mathrm{pH} 7.4)$ was slow and complete due to the FLB solubility at this $\mathrm{pH}$. Kinetic analysis of the release-profile of FLB from the formed beads was obeyed the diffusion mechanism. The post carrageenan injection showed reduction of swelling in groups treated with $\mathrm{Ca}$-alginate beads loaded-FLB with longer duration compared with the free FLB. The results showed that a simple and evaluated method for preparation of a modified-release Ca-alginate beads loaded-FLB for release for controlling of FLB with therapeutic purposes.
\end{abstract}

Keywords: Flurbiprofen; Modified-release preparation; Sodium alginate; Calcium alginate bead

\section{Introduction}

Flurbiprofen (FLB) a propionic acid derivative is a non-steroidal antiinflammatory drug (NSAID), used in the treatment of mild to moderate pains such as dysmenorrhea, migraine, and musculoskeletal. The oral doses of FLB are usually large daily divided doses (from 150 to 200 $\mathrm{mg}$ ) and may be increased to $300 \mathrm{mg}$ as in acute or severe conditions if necessary. As NSAIDs, FLB may be cause local gastrointestinal problems such as the sensation of warming or burning in the mouth and stomach, therefore it is recommended to be limited the use of FLB to a few days of treatment or use a modified-release preparations for only once daily-use [1]. Pharmacokinetically, FLB is readily absorbed from the gastrointestinal tract after the mentioned oral dose. $99 \%$ of FLB is bound to plasma proteins, the peak plasma concentrations occur after 1 to $2 \mathrm{hr}$ and its plasma half-life of 3 to 6 hours after administration $[1,2]$.

Alginic acid is an unbranched polymer of $\beta$-D-mannuronic acid (M) and $\alpha$-L-guluronic acid $(\mathrm{G})$ linked by 1-4-glycosidic linkages. Alginates form a hydrogel in the presence of certain divalent cations such as calcium $\left(\mathrm{Ca}^{2+}\right)$ ions. The gelling characteristics of alginates are influenced by the uronic acid composition and the MM/GG (mannuronic acid block/guluronic acid block) is an index of the nature of the gel that is formed in the presence of the divalent cations $[3,4]$. Caalginates have attracted much attention of the formulators as a potential device for controlling drug release. They have many advantages such as protection the stomach mucosa from the irritant drugs or protects the acid-sensitive drugs from gastric juice, the re-swelling process of xerogel (gel after drying) in the intestine offers a controlled-drug delivery, as well as their non-toxic orally administration [5-7]. Alginates are characterized by its re-swelling behavior which envisages the following advantages; acid sensitive drugs are protected from gastric juice, the re-swelling process of xerogel (gel after drying) in the intestine offers controlled-drug delivery. Alginate is known to be non-toxic when taken orally, it protects the mucosa of stomach from irritating drugs [7]. The amount of drug released from the beads at $\mathrm{pH} 1.5$ was relatively low which help in protecting the stomach from gastric irritation, whereas the release reaches to $99 \%$ at $\mathrm{pH} 6.8$. The drug can be encapsulated in nano-vesicle or micro-vesicle for local and systemic effect $[8,9]$. It was reported that, the released nifedipine and verapamil from the coated beads was minimal at $\mathrm{pH} 1.5$ (18\%), whereas approximately $99 \%$ nifedipine and verapamil was released at pH 6.8 [7,10]. Encapsulated nanoparticles or microparticles can be used for targeting certain site in the body [11-13]. The objective of this work was to utilize the alginate beads formulated with free FLB as a modified-release preparation for a few-daily usage to overcome the mentioned problems accompanied with FLB. The formed beads release FLB at $\mathrm{pH}$ 7.4, while can hold the $\mathrm{FLB}$ at $\mathrm{pH} 1.2$ which serve in protecting the stomach from the irritating effect of FLB.

\section{Materials and Methods}

\section{Materials}

All chemicals and reagents used were of pharmaceutical reagent grades and some of them were used as such without any further purification. FLB standard powder (Boots Co., Nottingham, U.K.) was kindly supplied by Al-Kahira pharmaceutical Co., Cairo, Egypt. Sodium alginate (Na-alginate), Carrageenan, Urethane, and calcium chloride $\left(\mathrm{CaCl}_{2}\right)$ were purchased from Sigma Chemical Co. (California, U.S.A.). Potassium chloride ( $\mathrm{KCl})$, hydrochloric acid ( $\mathrm{HCl})$, sodium hydroxide $(\mathrm{NaOH})$, acetic acid $\left(\mathrm{CH}_{3} \mathrm{COOH}\right)$, and potassium dihydrogen

*Corresponding authors: Abdellatif $\mathrm{AAH}$, Department of Pharmaceutics and Industrial pharmacy, Faculty of Pharmacy, Al Azhar University, Assuit 71524 Egypt, Tel: 201016660069; Fax: 20 882331711; E-mail: ahmed.a.h.abdellatif@ azhar.edu.eg

Received January 06, 2016; Accepted February 19, 2016; Published February 22, 2016

Citation: Abdellatif AAH, EI Hamd MA, Saleh KI (2016) A Formulation, Optimization and Evaluation of Controlled Released Alginate Beads Loaded-Flurbiprofen. J Nanomed Nanotechnol 7: 357. doi:10.4172/2157-7439.1000357

Copyright: ( 2016 Abdellatif AAH, et al. This is an open-access article distributed under the terms of the Creative Commons Attribution License, which permits unrestricted use, distribution, and reproduction in any medium, provided the original author and source are credited. 
orthophosphate $\left(\mathrm{KH}_{2} \mathrm{PO}_{4}\right)$ were purchased from El-Nasr Chemical Co. (Cairo, Egypt). A male Albino rats (weight 120-200 g) which used in the present study were obtained from Animal Hause, Assuit University (Assuit, Egypt). (Assuit University animal care use committee) permitted the animal procedures in this experiment. Spectrophotometric measurements were made using an UV-1601 spectrophotometer (Shimadzu, Kyoto, Japan) with two matched quartz cells.

\section{Experimental design}

Preparation and evaluation of Ca-alginate beads loaded flurbiprofen: The $\mathrm{Ca}$-alginate beads were prepared by dropping $\mathrm{Na}$ alginate solution which is $2 \mathrm{gm} \mathrm{Na}$-alginate in $100 \mathrm{~mL}$ water and containing $100 \mathrm{mg}$ of $\mathrm{FLB}$ on $100 \mathrm{~mL}$ solution of $0.2 \mathrm{M} \mathrm{CaCl}_{2}$ as reported previously $[14,15]$. The final homogenized solution filled into a $50 \mathrm{~mL}$ plastic syringe and dropped into a beaker containing $100 \mathrm{~mL}$ of $\mathrm{CaCl}_{2}$ (by the aid of stirring) until the Ca-alginate beads loadedFLB is spontaneously formed. For purification, the leached water was removed; the beads were washed with distilled water three times and then dried in an oven at $40^{\circ} \mathrm{C}$ for $12 \mathrm{hr}$. The dried beads were stored in a tightly closed glass container to avoid the moisture and humidity.

Ultraviolet spectroscopy: UV spectroscopy was used for determination of drug content and the amount of drug released from beads. Briefly, into a calibrated $500 \mathrm{~mL}$ stoppered conical flask, $100 \mathrm{mg}$ of the formed beads added and stirred with $500 \mathrm{~mL}$ of phosphate buffer (0.2 M, pH 7.4), mixed well by stirring overnight. $1 \mathrm{~mL}$ of this solution measured spectrophotometrically at $247 \mathrm{~nm}$. Then the actual drug concentration was calculated as:

$$
=\text { Absorbance } \times \text { proedural constant } \times 500 / 1000
$$

Differential scanning calorimetric (DSC): The effect of $\mathrm{CaCl}_{2}$ molar concentration and drug: alginate ratio (D: P) using a fixed concentration of $\mathrm{CaCl}_{2}$ solution, $0.2 \mathrm{M}$ on the diameter of the formed alginate beads was studied. DSC studies were carried out to confirm the obtained Ca-alginate D: P ratio, as well as the untreated drug, which indicated the extent of crystalinity of the drug in presence of the studied alginate. Two states were studied, the beads which prepared in different concentrations of $\mathrm{CaCl}_{2}$ and the effect of the different $\mathrm{D}: \mathrm{P}$ ratios (using one $\mathrm{CaCl}_{2}, 0.2 \mathrm{M}$ ). This method of analysis in as accordance of other results reported previously for other formula.

Characterization of the Ca-alginate beads loaded flurbiprofen: The diameter of the formed beads was determined with an opticalmicroscope at different positions and then the mean diameter of ten beads was calculated. The weight of the beads was determined as their water contents by weighing ten beads before and after drying, the average weight of ten beads was determined as the mean of five determinations and calculated as:

$$
\text { Water content, } \%=\frac{\text { weight before drying-weight after drying }}{\text { weight before drying }}
$$

The swelling percent (swelling percentage) of the dried beads was carried out in different medias (having different $\mathrm{pH}$ ) such as distilled water, $0.1 \mathrm{~N} \mathrm{HCl}$ (because it mimics the gastric $\mathrm{pH}$ of 1.2) and phosphate buffer $(0.2 \mathrm{M}, \mathrm{pH}$ 7.4). Thirty beads were placed into 500 $\mathrm{mL}$ of the medias and rotating $(50 \mathrm{rpm})$ for $(6 \mathrm{hr})$ at $37^{\circ} \mathrm{C}$. Three beads were taken out periodically and the diameter of each was measured at three different positions. The swelling percentage was expressed by the ratio of the average of these diameters of dried beads/average diameters of wetted beads [16]. The diameter of the formed beads before and after drying was performed using an optical microscope with power of microscope 100. The size and shape of the beads were drowning by putting a white paper and drawing the surface of beads using the background of the beads.

\section{In vitro release and kinetic analysis of flurbiprofen from Ca- alginate beads loaded flurbiprofen}

The release of alginate beads $\left(\mathrm{CaCl}_{2}, 0.2 \mathrm{M}\right.$ at 1:1 ratio) was studied in these medias and the study was focused on the release of FLB from alginate bead in phosphate buffer ( $\mathrm{pH}$ 7.4) prepared using different concentrations of $\mathrm{CaCl}_{2}$ solution or at fixed phosphate buffer $(0.2 \mathrm{M})$ and different ratios [17]. In these studies, a rotating basket apparatus method was utilized. An accurately weighed amount of Ca-alginate beads equivalent to $50 \mathrm{mg}$ of FLB was placed in a basket of USP validate-dissolution tester pre-filled with a dissolution medium (500 $\mathrm{mL}$ of each) and rotating $(50 \mathrm{rpm})$ for time at $37^{\circ} \mathrm{C} .1 \mathrm{~mL}$ of sample was withdrawn, periodically, diluted with appropriate volume of phosphate buffer (Beer's low between 0.1 and 1.0) and finally measure at 247 $\mathrm{nm}$. The removed samples were replaced with the same amount of phosphate buffer ( $\mathrm{pH} 7.4)[18,19]$. The released percentage was plotted against the square root of time, the slope and the Y-axis intercept can be deduced from such relation. The slope of this plot is a quantitative measure of the rate of drug release in cases when diffusion mechanism operates. The effect of different molar concentrations of $\mathrm{CaCl}_{2}$ and also the effect of $\mathrm{D}: \mathrm{P}$ ratios $\left(\right.$ at $\mathrm{CaCl}_{2}, 0.2 \mathrm{M}$ ) was checked to determine the diffusion rate constant $\left(\mathrm{K}_{\mathrm{h}}\right)$.

Evaluation of anti-inflammatory activity of beads loaded flurbiprofen: The anti-inflammatory activity of beads was checked by applying the method of carrageenan induced rat's paw edema [20]. Briefly, thirty-six male Albino rats were used; they randomly allocated to six groups each consists of six rats. Group I is control, group II is free alginate (blank), group III and IV are free FLB, and group V and VI are the formed beads-FLB. After animals were fasted overnight, they had given $3 \mathrm{~mL}$ of water (to reduce the variability to edema response) before the administration test of free alginate beads (blank beads), free FLB, and formed alginate beads loaded-FLB $(30 \mathrm{mg} / \mathrm{kg})$, the dose was chosen according to the previously reported results [21]. The rats were anesthetized with Urethane $(1.2 \mathrm{~g} / \mathrm{kg}$, intraprotnial). Each group was received the specified formula through a special gastric incubation into the esophagus (in a dose equivalent to $20 \mathrm{mg} / \mathrm{kg}$ ), followed by administration of the selected formulae. After $2 \mathrm{hr}$ of formulae administration, $0.1 \mathrm{~mL}$ of carrageenan solution $(1 \%$, w/v) was injected subcutaneously into sub-planator tissue of one hind paw to induce the inflammation. The thickness of the paw edema was measured using a micrometer, and determined before and immediately after injection of carrageenan. Subsequent measurements were carried out at 1, 2, 3, 4, 5 and $6 \mathrm{hr}$ after induction of edema. The anti-inflammatory effect was expressed as an inhibition percentage of edema thickness compared with control group according to the following equation.

$$
\text { Inhibation of edema, } \%=\frac{T_{0}-T_{t}}{T_{0}} \times 100 \%
$$

Where, $\mathrm{T}_{0}$ is the edema thickness in control group, $\mathrm{T}_{t}$ is the edema

thickness in treated group. Then the obtained results were tested for a significantly difference by using one-way ANOVA test in SPSS software package (version 9). 


\section{Results and Discussion}

As previously reported, sodium alginate is dropped to a solution of calcium chloride, a gel formed as the sodium ions was exchanged with calcium ions and the polymer cross-linked together. When the alginate is longer in contact with the calcium chloride solution, more rigid gel will become and more cross-links with the calcium ions can be formed [14-15].

\section{Differential scanning calorimetry study}

In order to shed a light on the possibility of solid-state changes of FLB with alginate polymer, DSC was performed on the individual components and the physical mixture of beads. The DSC curve of the untreated FLB and the free sodium alginate shows an endothermic peak at $113.3^{\circ} \mathrm{C}$ and $250.3^{\circ} \mathrm{C}$, respectively at a scanning rate of $10^{\circ} \mathrm{C} / \mathrm{min}$. The DSC thermogram of the obtained Ca-alginate blank beads shows no endothermic peak at $250.3^{\circ} \mathrm{C}$. While, The thermogram of alginate beads loaded-FLB, at $1: 1$ ratio and dropped in $0.2 \mathrm{M}^{\circ} \mathrm{CaCl}_{2}$, shows two endotherms at $250.4^{\circ} \mathrm{C}$ and $114.2^{\circ} \mathrm{C}$ with energies of $16.1 \mathrm{~J} / \mathrm{g}$ and $81.0 \mathrm{~J} / \mathrm{g}$, respectively. The endothermic peak of the drug exists at the same position compared to the untreated drug $\left(113.3^{\circ} \mathrm{C}\right)$, Figure 1A. The same results were obtained with FLB alginate beads at 1:0.5 ratio and dropped in $\mathrm{CaCl}_{2}, 0.2 \mathrm{M}$, but the endothermic peak of the drug and polymer with low distinct sharpened appearance than the former type which indicates that there is no interaction between the drug and the polymer as shown in Figure 1B.

\section{Characterization and evaluation of Ca-alginate beads loaded flurbiprofen}

The formed alginate beads had big sizes and heavy weights before drying as they hold an amount of water about $94 \%$ calculated after drying, Table 1. This amount of water aided in the formation of spherical beads with smooth surface as shown in Figure 2. The size and weight was decreased significantly of dried beads, due to the loss of water of about $0.30 \%$ in the beads.

\section{Microscopic examination of Ca-alginate beads}

A freshly prepared spherical-shape Ca-alginate bead before drying is shown in the photomicrographs, Figure 2A. Gelation seemed to occur instantly on the surface of the droplets forming almost spherical beads without splashing of the fallen droplets (distance of fallen droplets was $20 \pm 5 \mathrm{~cm}$ ). Figure $2 \mathrm{~B}$ shows a dried plain alginate gel bead which became less spherical and their size decreased significantly. Figure 3 shows the shape and the surface of beads at 1:1 ratio. The beads are spherical with granulated surface. The crystals seen on the surface could be formed during drying due to insolubility of the drug and the shrinkage of alginate beads. Where, the loaded drug was greater, the crystals seemed with bigger size covered by the alginate. Hence, the beads cover appeared to be improved when the matrices were produced from a more concentrated drug suspension at the same time, fissures appeared clearly with the increased the alginate content.

The effect of $\mathrm{CaCl}_{2}$ concentration on the diameter of the formed alginate beads and the effect of $\mathrm{D}: \mathrm{P}$ ratios at a fixed $\mathrm{CaCl}_{2}$ solution were studied. The data in Table 2 revealed that the alginate beads diameter increases as the molar concentration of $\mathrm{CaCl}_{2}$ decreases. It was obvious that, the beads were shrunk significantly during drying and had a small size (diameter $\approx 1.32-1.78 \mathrm{~mm}$ ). Less shrinkage with bigger beads size was observed with either increase in amount of loaded (loaded) FLB or with decrease for $\mathrm{CaCl}_{2}$.

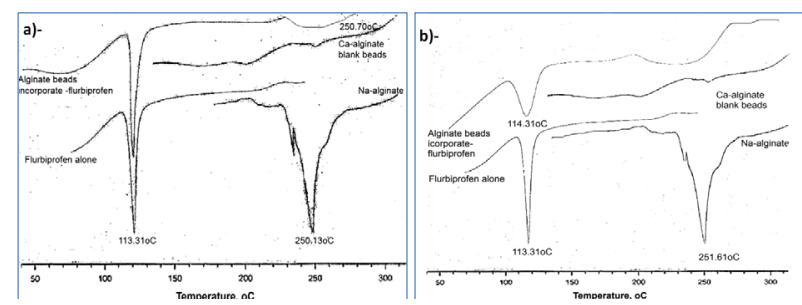

Figure 1: DSC curves of free FLB, Na-alginate, Ca-alginate, alginate beads loaded $\mathrm{FLB}$ in $\mathrm{CaCl}_{2}, 0.2 \mathrm{M}$, and using 1:1 ratio, $(\mathrm{A})$ and 1:0.5 ratio, (B).

\begin{tabular}{|c|c|c|}
\hline Beads Property & Before drying & After drying \\
\hline Diameter, mm & $2.22 \pm 0.07$ & $0.808 \pm 0.04$ \\
\hline Weight, mg/bead & $7.55 \pm 0.21$ & $0.418 \pm 0.01$ \\
\hline Water content & $94.46 \%$ & $(0.30 \%)$ \\
\hline
\end{tabular}

Table 1: Physical properties of plain Ca-alginate beads loaded-FLB before and after drying

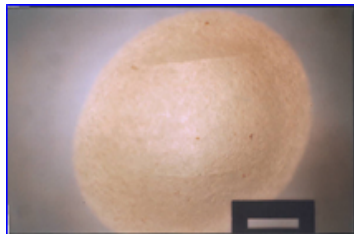

Freshly prepared plain alginate beads

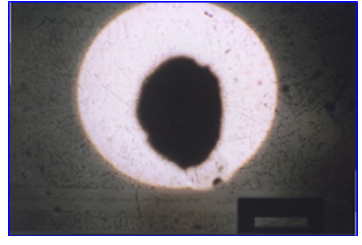

b. Dried plain alginate bead
Figure 2: Photograph taken by optical microscope with camera Lucida (Carl Zeiss) for the formed alginate beads.

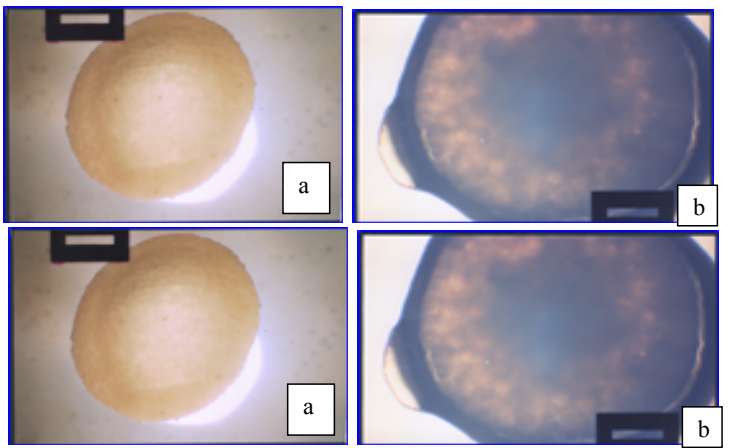

Figure 3: Photographs of the formed alginate beads prepared at 1:1 ratio. (a) Freshly prepared alginate beads loaded FLB at 1:1D:P ratio and $\mathrm{CaCl}_{2}, 0.2 \mathrm{M}$. (b) Freshly prepared alginate beads loaded FLB at 1: $1 \mathrm{D}: \mathrm{P}$ ratio and $\mathrm{CaCl} 2,02 \mathrm{M}$, with high magnification power. (c). Dried alginate beads loaded FLB at 1:1D: $\mathrm{P}$ ratio and $0.2 \mathrm{M} \mathrm{CaCl}$, after swelling. (d). Re-swelled alginate beads loaded FLB 1:1D: $\mathrm{P}$ ratio and $0.2 \mathrm{M} \mathrm{CaCl}$.

\section{Swelling percentage of Ca-alginate beads loaded flurbiprofen}

FLB powder is sparingly soluble in water at low $\mathrm{pH}$ values but readily soluble in $\mathrm{pH}$ above 7 [22]. The swelling percentage and consequently the release efficiency are necessary to be checked in a different medias having different $\mathrm{pH}$. However, the swelling percentage of Ca-alginate beads in phosphate buffer was greater than its original size through 1-1.5 hr. The disintegration and dispersion are gradually occurring over more than one hr. Furthermore, the matrices remained intact in spite 
Citation: Abdellatif AAH, El Hamd MA, Saleh KI (2016) A Formulation, Optimization and Evaluation of Controlled Released Alginate Beads LoadedFlurbiprofen. J Nanomed Nanotechnol 7: 357. doi:10.4172/2157-7439.1000357

Page 4 of 8

\begin{tabular}{|c|c|c|c|c|c|}
\hline \multirow{2}{*}{$\begin{array}{l}\text { (A) Molar concentration of } \\
\mathrm{CaCl}_{2}(1: 1 \text { ratio })\end{array}$} & \multicolumn{2}{|c|}{ Diameter of beads, $\mathrm{mm}$} & \multirow{2}{*}{ Weight of beads, mg } & \multirow{2}{*}{ Loaded-FLB, (mg) } & \multirow{2}{*}{$\begin{array}{c}\text { Encapsulation efficiency, } \\
\text { percentage }\end{array}$} \\
\hline & before drying & after drying & & & \\
\hline 0.025 & $2.6 \pm 0.1$ & $1.6 \pm 0.1$ & $0.7 \pm 0.0$ & $49.4 \pm 0.5$ & 98.7 \\
\hline 0.05 & $2.1 \pm 0.1$ & $1.6 \pm 0.1$ & $0.6 \pm 0.0$ & $45.7 \pm 0.5$ & 91.3 \\
\hline 0.1 & $2.2 \pm 0.1$ & $1.5 \pm 0.1$ & $0.6 \pm 0.0$ & $43.8 \pm 0.5$ & 87.6 \\
\hline 0.2 & $2.1 \pm 0.0$ & $1.4 \pm 0.2$ & $0.6 \pm 0.0$ & $42.6 \pm 0.6$ & 85.2 \\
\hline 0.5 & $2.0 \pm 0.3$ & $1.4 \pm 0.0$ & $0.5 \pm 0.0$ & $36.6 \pm 0.5$ & 73.5 \\
\hline 1.0 & $20.0 \pm 0.1$ & $1.3 \pm 0.1$ & $0.6 \pm 0.0$ & $33.1 \pm 0.5$ & 66.1 \\
\hline \multirow{2}{*}{ (B) D:P ratios } & \multicolumn{2}{|c|}{ Diameter of beads, $\mathrm{mm}$} & & & Encapsulation efficiency \\
\hline & before drying & after drying & Weight of beads, mg & Loaded-FLB, mg & percentage \\
\hline $1: 0.5$ & $2.8 \pm 0.1$ & 1. $8 \pm 0.1$ & $0.6 \pm 0.1$ & $49.3 \pm 0.5$ & 98.5 \\
\hline 1: 1 & $2.6 \pm 0.1$ & $1.6 \pm 0.1$ & $0.7 \pm 0.1$ & $45.6 \pm 0.5$ & 91.3 \\
\hline $1: 2$ & $2.7 \pm 0.1$ & $1.5 \pm 0.1$ & $0.6 \pm 0.1$ & $42.5 \pm 0.5$ & 84.9 \\
\hline $1: 3$ & $2.7 \pm 0.1$ & $1.6 \pm 0.1$ & $0.7 \pm 0.1$ & $41.1 \pm 0.5$ & 82.1 \\
\hline $1: 4$ & 1. $8 \pm 0.1$ & $1.4 \pm 0.1$ & $0.5 \pm 0.2$ & $35.2 \pm 0.5$ & 70.2 \\
\hline $1: 5$ & $2.1 \pm 0.1$ & $1.3 \pm 0.1$ & $0.5 \pm 0.1$ & $29.9 \pm 0.5$ & 59.8 \\
\hline
\end{tabular}

Table 2: Characterization of $\mathrm{Ca}$-alginate beads, prepared in different concentrations of $\mathrm{CaCl} 2$, at $1: 1$ ratios $(\mathrm{A})$; and their characterization after preparation in $\mathrm{CaCl} 2,0.2$ $M$ at different $D$ : $P$ ratios (B).

of conversion of Ca-alginate beads to alginic acid having a transparent appearance. Figure 4 shows the difference in the swelling percentage of Ca-alginate beads in these media.

\section{In vitro release of flurbiprofen from the Ca-alginate beads loaded flurbiprofen}

Most of the release data were shown to follow diffusion-controlled mechanism $[23,24]$. The release profile of loaded-FLB from the alginate beads in water and in $0.1 \mathrm{~N} \mathrm{HCl} \mathrm{pH} 1.2$ was showed in Figure 5. The release demonstrates a high retardation of FLB from alginate beads. Only $3.6 \%$ and $4.8 \%$ of drug content in the beads were released after two hr in water and $0.1 \mathrm{~N}$ hydrochloric acid $\mathrm{pH} 1.2$, respectively. The low release of FLB indicates that alginate beads could serve as reservoir for FLB release prolongation.

The release-profile of FLB from alginate beads prepared using different concentrations of $\mathrm{CaCl}_{2}$ was slow compared with plain drug, this is due to low solubility of FLB as well as the slight swelling of alginate in the phosphate buffer. Alginate beads with a higher concentration of $\mathrm{Ca}^{2+}$ ions demonstrated a slower rate and lower extent of drug release. While, alginate beads prepared in $\mathrm{CaCl}_{2}, 0.025 \mathrm{M}$ ( $1: 1$ ratio) has a high release rate and high drug loaded (Figure 6). Next, the results revealed that the release rate was relatively faster with the increase in alginate contents. Figure 7 shows the effect of different ratios of D:P on the release-profile of FLB from the formed alginate beads, when prepared in $\mathrm{CaCl}_{2}, 0.2 \mathrm{M}$. Alginate beads prepared at 1: 0.5 ratios shows a high release rate and high incorporating-drug. While alginate beads prepared at 1: 5 ratio shows a low drug release and low incorporatingdrug. As the result shows the alginate beads prepared at 1: 1 ratio in $\mathrm{CaCl}_{2}, 0.2 \mathrm{M}$ was used for the further studies as the best type of beads as it have a moderate release rate and moderate drug loading.

\section{Kinetic analysis of release-profile of flurbiprofen from the} Ca-alginate beads loaded flurbiprofen

The diffusion matrix results are shown in Table 3 for release percentage data was obeyed the diffusion mechanism, these data were supported by previously results [25]. The results were revealed, the $\mathrm{K}_{h}$ (while the other parameters were fixed) from $\mathrm{CaCl}_{2}$ beads 0.025 and $0.05 \mathrm{M}$ was 4.048 and $4.176 / \mathrm{min}$. Further increase the concentration of $\mathrm{CaCl}_{2}$ from $0.1 \mathrm{M}$ to $1 \mathrm{M}$, decreased the value of $\mathrm{K}_{h}$ from 3.904 to 3.639 / min. while, increasing the polymer ratio in D:P ratios (from 1:0.5 to

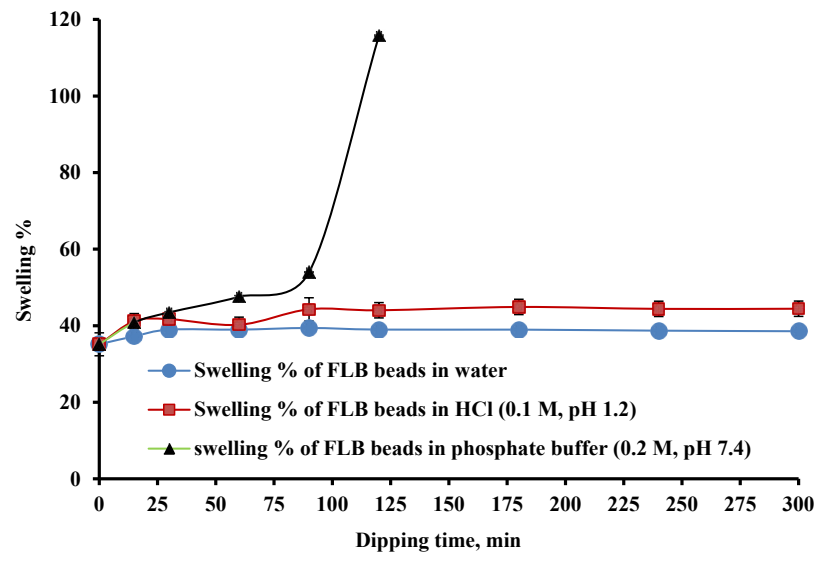

Figure 4: Swelling percentage of FLB beads, in water, in $\mathrm{HCl}(0.1 \mathrm{M}, \mathrm{pH} 1.2)$ and in phosphate buffer $(0.2 \mathrm{M}, \mathrm{pH} 7.4)$.

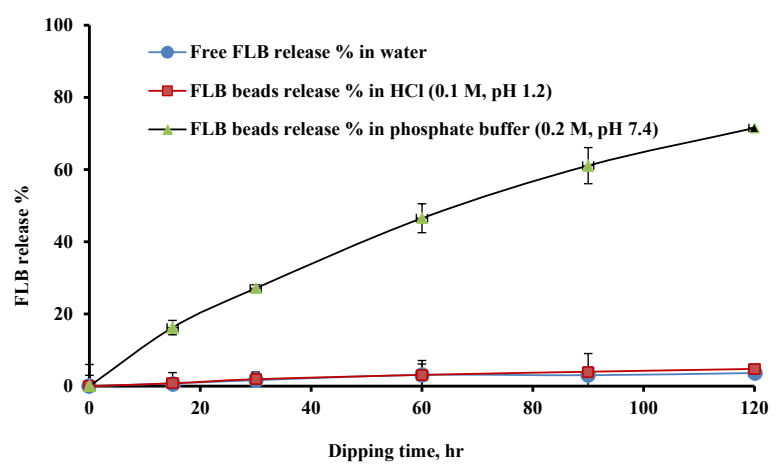

Figure 5: Release percentage of free FLB and FLB beads, in water and $\mathrm{HCl}(0.1 \mathrm{M}, \mathrm{pH} 1.2)$

1:5) increased the value of $\mathrm{K}_{h}$ from 4.211 to $4.66 / \mathrm{min}$.

Evaluation of anti-inflammatory activity of Ca-alginate beads loaded flurbiprofen

The result in Figure 8 illustrates the anti-inflammatory effect of free 


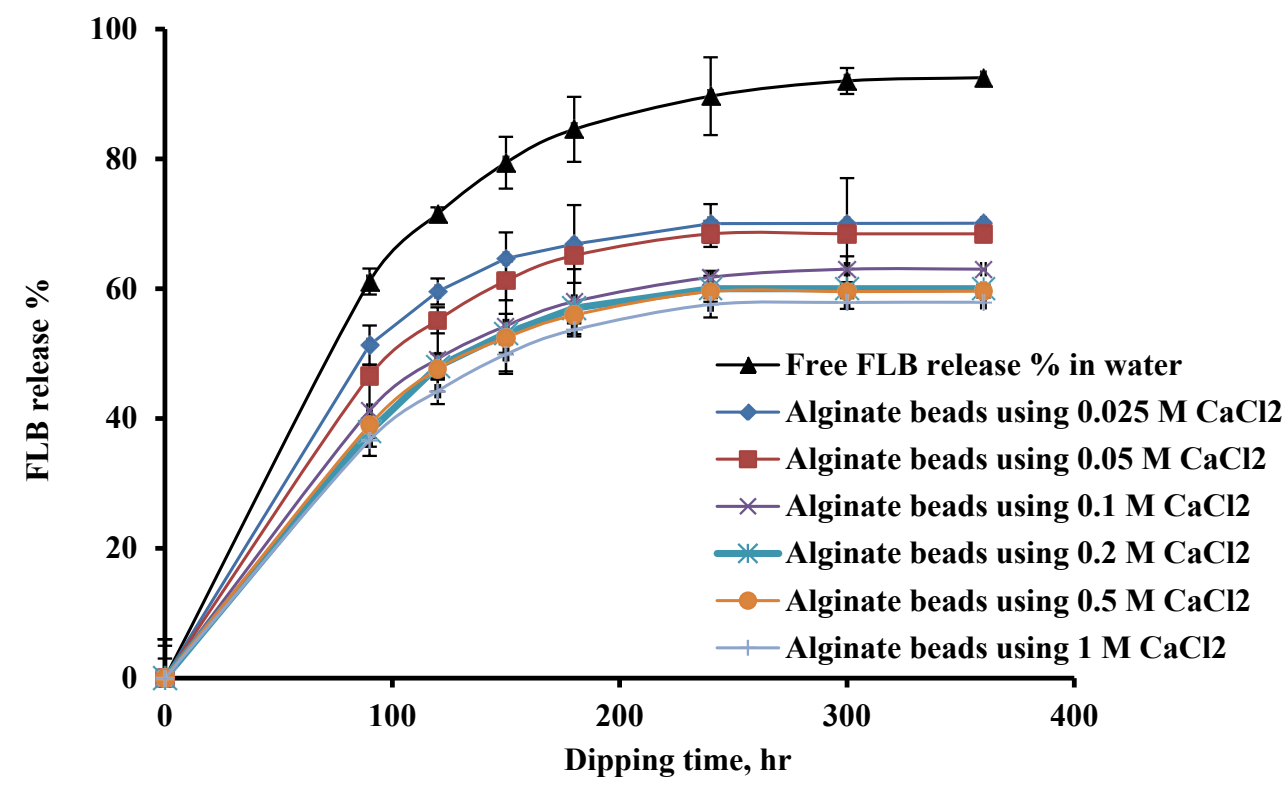

Figure 6: Release percentage of FLB beads in phosphate buffer $(0.2 \mathrm{M}, \mathrm{pH} 7.4)$ using different concentration of $\mathrm{CaCl}_{2}$ (at $1: 1$ ratio)

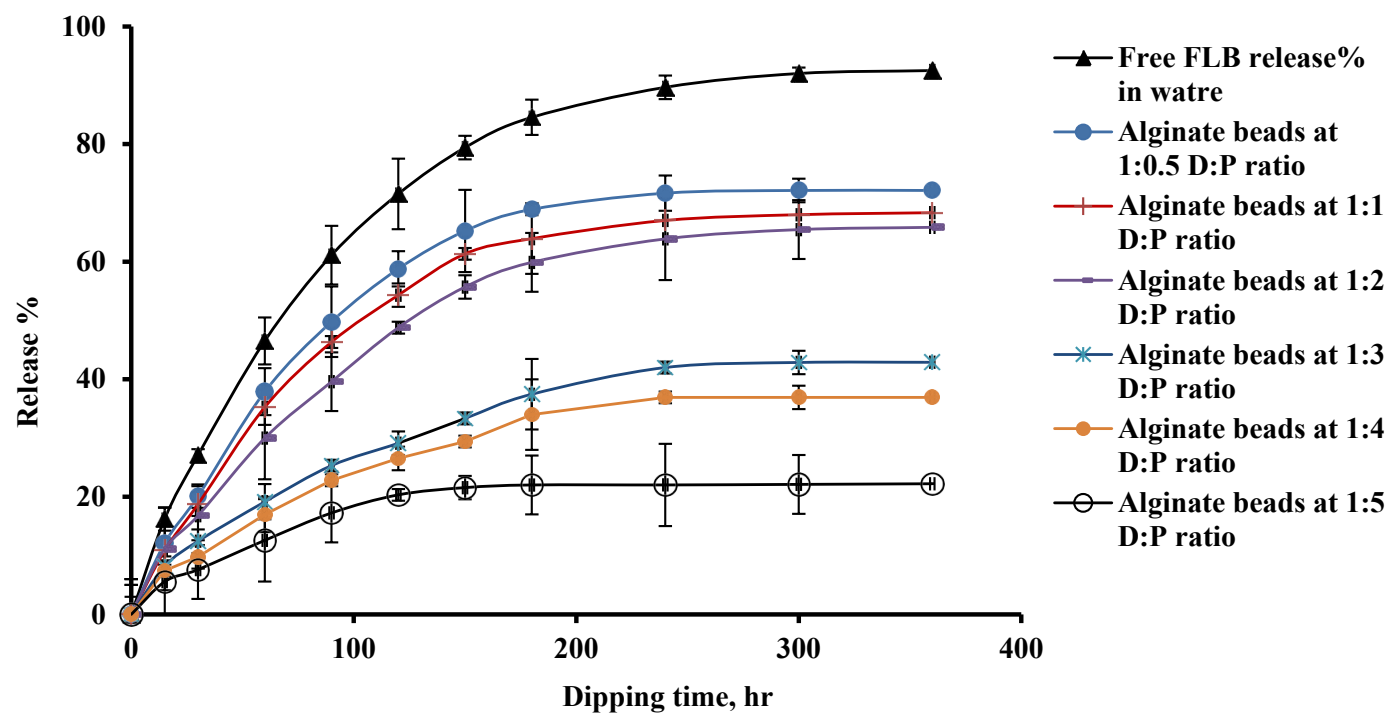

Figure 7: Effect of different $\mathrm{D}$ : $\mathrm{P}$ ratio on the release percentage of FLB beads in phosphate buffer $\left(0.2 \mathrm{M}, \mathrm{pH}^{7.4}\right) \mathrm{using} \mathrm{CaCl}_{2}(0.2 \mathrm{M})$.

alginate beads, free FLB, and alginate beads loaded-FLB. It is obvious that at $1 \mathrm{hr}$ post carrageenan injection, there is apparent reduction of swelling in groups treated with alginate beads loaded-FLB (V, VI), and free drug (groups III, IV) compared with the control group (group I). There is no evident inhibition in edema swelling in group II.

The inhibition percentage of edema swelling using the group V, VI, and group III, IV, were 12.3 and 14.1 versus 6 for the group II. After $2 \mathrm{hr}$ post carrageenan injection the anti-edema effect was higher in group V, VI, and groups III, IV, where the inhibition $\%$ of edema swelling was 23.1, and 33 versus 1.84 into group II. After $5 \mathrm{hr}$ post carrageenan injection the anti-edema effect of alginate beads loaded-FLB was higher, where the inhibition percentage of edema swelling was 51.9 versus 18.12 in group III, IV. Next, $6 \mathrm{hr}$ post carrageenan injection groups V, VI, still exhibited a significant inhibition of the carrageenan induced edema, which is numerically higher than that observed in the rats in groups II or III, IV, where the inhibition percentage in edema swelling was 41.4 versus 2.71 and 6.7 in groups II and III, IV respectively, as shown in Figure 8.

Table 4 shows the statistical analysis (correlation bivariate two tailed analysis) of control, blank alginate beads, and alginate beads loaded-FLB. The correlation is significant different at probability levels, 0.05 and 0.01 . The significant results are 0.93 and 0.80 , respectively.

One-way ANOVA test of inhibition percentage in rat paw edema of control, blank alginate beads, and alginate beads loaded-FLB is shown 
Citation: Abdellatif AAH, El Hamd MA, Saleh KI (2016) A Formulation, Optimization and Evaluation of Controlled Released Alginate Beads LoadedFlurbiprofen. J Nanomed Nanotechnol 7: 357. doi:10.4172/2157-7439.1000357

Page 6 of 8

\begin{tabular}{|c|c|c|c|c|c|c|c|}
\hline \multirow{2}{*}{\multicolumn{2}{|c|}{ (A) Mechanism of release }} & \multicolumn{6}{|c|}{ Different $\mathrm{CaCl}_{2}$ concentration, $\mathrm{M}$} \\
\hline & & 0.025 & 0.05 & 0.1 & 0.2 & 0.5 & 1 \\
\hline \multirow{2}{*}{$1^{\text {st }}$ order } & $\mathrm{r}$ & -0.878 & -0.896 & -0.922 & -0.866 & -0.896 & -0.917 \\
\hline & $\mathrm{K}_{1} / \mathrm{min}$ & -0.001 & -0.001 & -0.001 & -0.001 & -0.001 & -0.001 \\
\hline \multirow{2}{*}{ Zero order } & $\mathrm{r}$ & 0.834 & 0.855 & 0.873 & 0.838 & 0.866 & 0.879 \\
\hline & $\mathrm{K}_{0}$, release percentage $/ \mathrm{min}$ & 0.157 & 0.1637 & 0.154 & 0.148 & 0.146 & 0.144 \\
\hline \multirow{2}{*}{ Higuchi's diffusion } & $r$ & 0.923 & 0.938 & 0.949 & 0.923 & 0.943 & 0.952 \\
\hline & $\mathrm{K}_{\mathrm{h}}$, release percentage /min & 4.048 & 4.176 & 3.904 & 3.799 & 3.709 & 3.639 \\
\hline \multirow{2}{*}{ Log $Q$ Vs. $\log t$} & $r$ & 0.952 & 0.957 & 0.964 & 0.959 & 0.953 & 0.969 \\
\hline & Slope & 0.5805 & 0.448 & 0.467 & 0.497 & 0.536 & 0.475 \\
\hline \multicolumn{2}{|c|}{ Best fitted model } & \multicolumn{6}{|c|}{$\mathrm{k}_{\mathrm{h}}$} \\
\hline \multirow{2}{*}{\multicolumn{2}{|c|}{ (B) Mechanism of release }} & \multicolumn{6}{|c|}{ Drug: polymer ratios } \\
\hline & & $1: 0.5$ & 1:1 & $1: 2$ & $1: 3$ & 1:4 & 1:5 \\
\hline \multirow{2}{*}{$1^{\text {st }}$ order } & $r$ & -0.899 & -0.972 & -0.922 & -0.936 & -0.922 & -0.814 \\
\hline & $\mathrm{K}_{1} / \min$ & -0.002 & -0.001 & -0.001 & -0.001 & -0.001 & -0.001 \\
\hline \multirow{2}{*}{ Zero order } & r & 0.853 & 0.977 & 0.873 & 0.897 & 0.907 & 0.805 \\
\hline & $\mathrm{K}_{0}$, release percentage/ min & 0.163 & 0.088 & 0.154 & 0.158 & 0.0878 & 0.045 \\
\hline \multirow{2}{*}{ Higuchi's diffusion } & r & 0.936 & 0.997 & 0.949 & 0.963 & 0.967 & 0.901 \\
\hline & $\mathrm{K}_{\mathrm{h}}$, release percentage /min & 4.211 & 2.088 & 3.904 & 3.951 & 2.171 & 1.166 \\
\hline $\log Q$ Vs. $\log t$ & $r$ & 0.981 & 0.915 & 0.964 & 0.981 & 0.983 & 0.951 \\
\hline \multicolumn{2}{|c|}{ Best fitted model } & \multicolumn{6}{|c|}{$\mathrm{k}_{\mathrm{h}}$} \\
\hline
\end{tabular}

Table 3: Kinetic study of drug release percentage from FLB beads at different CaCl2 concentration and 1:1D: $P$ ratio (A); and Kinetic study of drug release percentage from alginate beads at $\mathrm{CaCl} 20.2 \mathrm{M}$ and different $\mathrm{D}: \mathrm{P}$ ratios in phosphate buffer $(25 \pm 5 \mathrm{OC})(\mathrm{B})$.

\begin{tabular}{|c|c|c|c|c|c|c|c|c|}
\hline \multirow{2}{*}{ Factors } & \multicolumn{2}{|c|}{ Control } & \multicolumn{2}{|c|}{ Free alginate beads } & \multicolumn{2}{|c|}{ Free FLB } & \multicolumn{2}{|c|}{ Alginate beads loaded-FLB } \\
\hline & $\mathbf{r}$ & Sign. ${ }^{1}$ & $\mathbf{r}$ & Sign. ${ }^{1}$ & $\mathbf{r}$ & Sign. ${ }^{1}$ & $\mathbf{r}$ & Sign. ${ }^{1}$ \\
\hline Time, min & 0.83 & $* *$ & 0.26 & --- & 0.52 & --- & 0.19 & --- \\
\hline Control & & & 0.12 & --- & 0.30 & --- & 0.43 & --- \\
\hline FLB beads & & & & & 0.38 & --- & 0.54 & --- \\
\hline Free FLB & & & & & & & 0.99 & $* *$ \\
\hline
\end{tabular}

1 Significant difference

Table 4: Statistical analysis of control, blank alginate beads and FLB beads on the carrageenan-induced edema in the hind paw of rats.

\begin{tabular}{|c|c|c|c|c|c|c|}
\hline \multicolumn{2}{|c|}{ Dosage form } & \multirow{2}{*}{$\frac{\text { Summation of squares }}{7.82}$} & \multirow{2}{*}{$\frac{\text { DF }^{1}}{4}$} & \multirow{2}{*}{$\begin{array}{c}\text { Mean of square } \\
1.95\end{array}$} & \multirow{2}{*}{$\frac{F^{2}}{0.99}$} & \multirow{2}{*}{$\begin{array}{r}\text { Sign. }^{3} \\
0.63\end{array}$} \\
\hline \multirow{3}{*}{ Free alginate beads } & Between groups & & & & & \\
\hline & Within groups & 1.98 & 1 & 1.98 & & \\
\hline & Total & 9.81 & 5 & & & \\
\hline \multirow{3}{*}{ Free FLB } & Between groups & 702.23 & 4 & 175.56 & 0.41 & 0.81 \\
\hline & Within groups & 426.32 & 1 & 426.32 & & \\
\hline & Total & 1128.55 & 5 & & & \\
\hline \multirow{3}{*}{ FLB beads } & Between groups & 638.98 & 4 & 159.74 & 0.30 & 0.88 \\
\hline & Within groups & 529.43 & 1 & 529.43 & & \\
\hline & Total & 1168.4 & 5 & & & \\
\hline \multirow{3}{*}{ Control } & Between groups & 17.98 & 4 & 4.51 & 0.84 & 0.67 \\
\hline & Within groups & 5.38 & 1 & 5.38 & & \\
\hline & Total & 23.36 & 5 & & & \\
\hline
\end{tabular}

Table 5: One way ANOVA test for inhibition percentage of rat paw edema.

in Table 5. The results obtained revealed that the selected alginate beads loaded-FLB have an anti-inflammatory activity with long duration of action.

\section{Conclusion}

In conclusion, the present study reveals the characteristics of FLBloaded alginate bead formulations; drug loading, polymer percentage and the Molar concentration of $\mathrm{CaCl}_{2}$ used influenced the encapsulation efficiency and in vitro drug release characteristics of the prepared beads. Ca-alginate loaded-FLB, a macro-encapsulation delivery system was investigated for the solubility enhancement and improving the bioavailability of water insoluble FLB drug, using Ca-alginate beads formulae. Moreover, it is a novel method to prepare efficient antiinflammatory FLB beads which able to mask the drug taste and its burring effect in the oral cavity and stomach. The gastro protective effect of flurbiprofen-loaded alginate beads was the main achievement 


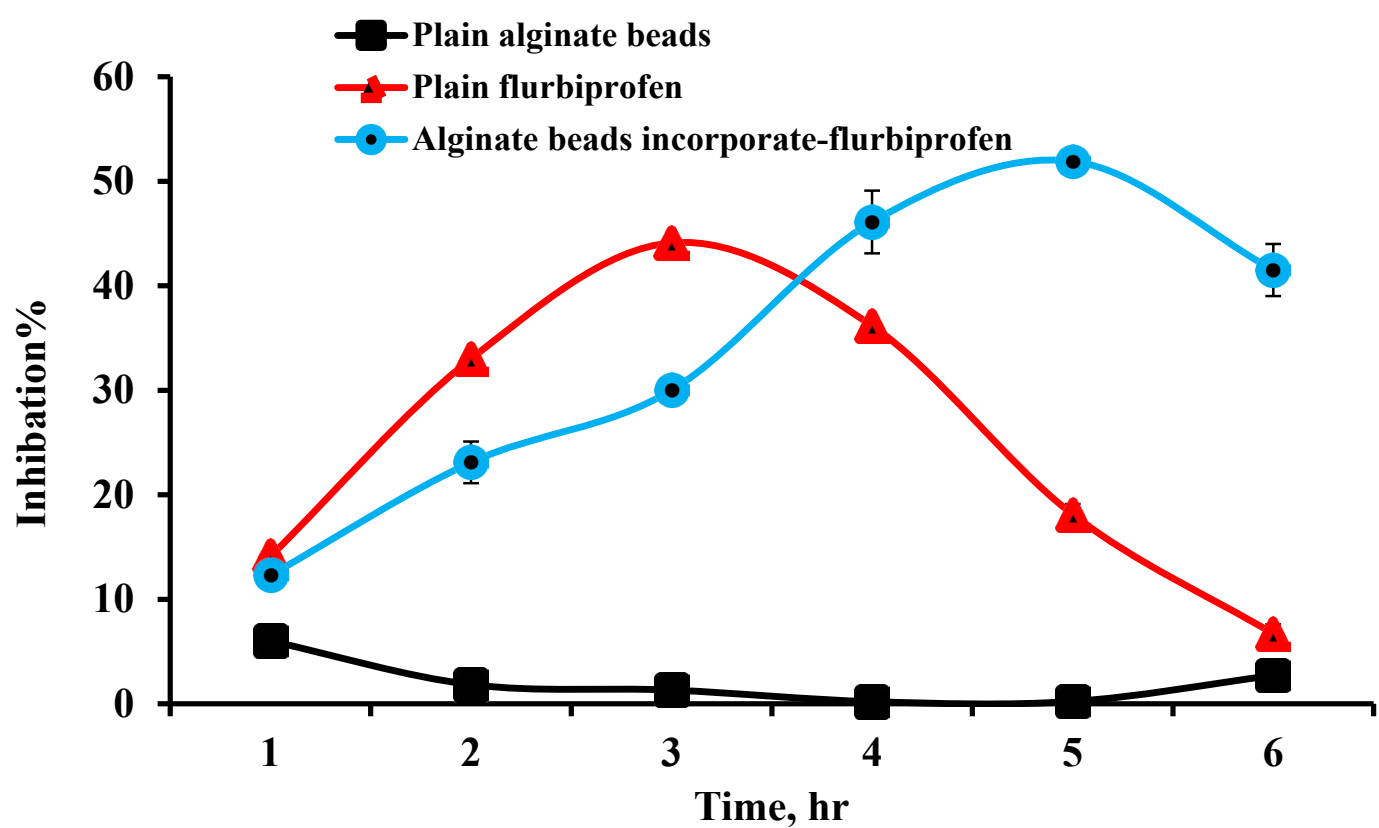

Figure 8: Inhibition percentage of rat paw induced edema for the selected formulae.

of this study. Therefore, these beads are promising pharmaceutical forms, which provide controlled-release drug delivery systems and covering the gastric effect of NSAIDs.

\section{Conflict of Interest}

Authors declare no conflict of interest.

\section{References}

1. Sweetman SC (2009) Martindale: The complete drug reference. NUB Digital Institutional Repository and Library, London.

2. Wang CL, Lin WW, Gong SJ, Huang PF (2010) [Population pharmacokinetic modeling of flurbiprofen]. Yao Xue Xue Bao 45: 1427-1432.

3. Kuanga K, Dub J, Zhouc R, Chena Z, Megharaj M, et al. (2015) Calcium alginate encapsulated $\mathrm{Ni} / \mathrm{Fe}$ nanoparticles beads for simultaneous removal of Cu (II) and monochlorobenzene. J Colloid Interface Sci 447: 85-91.

4. Agarwal T, Narayana SN, Pal K, Pramanik K, Giri S, et al. (2015) Calcium alginate-carboxymethyl cellulose beads for colon-targeted drug delivery. Int $\mathrm{J}$ Biol Macromol 75: 409-417.

5. Al-Otoum R, Abulateefeh SR, Taha MO (2014)Preparation of novel ionotropically crosslinked beads based on alginate-terephthalic acid composites as potential controlled release matrices. Pharmazie 69: 10-18.

6. Liakos I, Rizzello L, Bayer IS, Pompa PP, Cingolani R, et al. (2013) Controlled antiseptic release by alginate polymer films and beads. Carbohydr Polym 92 176-183.

7. Dai YN, Li P, Zhang JP, Wang AQ, Wei Q (2008) Swelling characteristics and drug delivery properties of nifedipine-loaded $\mathrm{pH}$ sensitive alginate-chitosan hydrogel beads. J Biomed Mater Res Appl Biomater 86: 493-500.

8. Abdellatif AAH, Abou-Taleb HA (2016) Transfersomal nanoparticles of keratolytic and antibacterial agents for enhanced transdermal delivery. Journal of Nanotechnology and Advanced Materials 4: 19-23.

9. Abdellatif AA, Abou-Taleb HA (2015) optimization of nano-emulsion formulations for certain emollient effect. World Journal of Pharmacy and Pharmaceutical Sciences 4: 1314-1328
10. Pasparakis G, Bouropoulos N (2006) Swelling studies and in vitro release of verapamil from calcium alginate and calcium alginate-chitosan beads. Int $J$ Pharm 323: 34-42.

11. Abdellatif AA, Tawfeek HM (2015) Transfersomal Nanoparticles for enhanced transdermal delivery of clindamycin. AAPS Pharm Sci Tech [Epub ahead of print].

12. Abdellatif, AA, Rasoul SAE, Osman S (2015) Gold nanoparticles decorated with octreotide for somatostatin receptors targeting. Int J Pharm Sci Res 7: 14-20.

13. Abdellatif AA (2015) Targeting of somatostatin receptors using quantum dots nanoparticles decorated with octreotide. Journal of Nanomedicine and Nanotechnology S6: 005.

14. Zhao Y, Carvajal MT, Won Y, Harris MT (2007) Preparation of calcium alginate microgel beads in an electrodispersion reactor using an internal source of calcium carbonate nanoparticles. Langmuir 23: 12489-12496.

15. Fathy M, Safwat SM, el-Shanawany SM, Shawky Tous S, Otagiri M (1998) Preparation and evaluation of beads made of different calcium alginate compositions for oral sustained release of tiaramide. Pharm Dev Technol 3: 355-364.

16. Wang Q, Xiec X, Zhangc X, Zhanga J, Wan A, et al. (2010) Preparation and swelling properties of $\mathrm{pH}$-sensitive composite hydrogel beads based on chitosan-g-poly (acrylic acid)/vermiculite and sodium alginate for diclofenac controlled release. Int J Biol Macromol 46: 356-62.

17. Al-Taani B, Khanfar MS, Salem MS, Sallam A (2010) Release behaviour of diclofenac sodium dispersed in Gelucire and encapsulated with alginate beads. J Microencapsul 27: 10-13

18. Ma Y, Li WZ, Guan SX, Lai XP, Chen DW (2009) Evaluation of tetrandrine sustained release calcium alginate gel beads in vitro and in vivo. Yakugaku Zasshi 129: 851-854.

19. Downs EC, Robertson NE, Riss TL, Plunkett ML (1992) Calcium alginate beads as a slow-release system for delivering angiogenic molecules in vivo and in vitro. J Cell Physiol 152: 422-429.

20. Sakat SS, Mani K, Demidchenko YO, Gorbunov EA, Tarasov SA, et al. (2014) Release-active dilutions of diclofenac enhance anti-inflammatory effect of diclofenac in carrageenan-induced rat paw edema model. Inflammation 37: $1-9$ 
Citation: Abdellatif AAH, El Hamd MA, Saleh KI (2016) A Formulation, Optimization and Evaluation of Controlled Released Alginate Beads LoadedFlurbiprofen. J Nanomed Nanotechnol 7: 357. doi:10.4172/2157-7439.1000357

Page 8 of 8

21. Kukar T, Prescott S, Eriksen JL, Holloway V, Murphy MP, et al. (2007) chronic administration of R-flurbiprofen attenuates learning impairments in transgenic amyloid precursor protein mice. BMC Neurosci 8: 54

22. Baviskar DT, Amritkar AS, Chaudhari HS, Jain DK (2012) Modulation of drug release from nanocarriers loaded with a poorly water soluble drug (flurbiprofen) comprising natural waxes. Pharmazie 67: 701-705.

23. Liu CH., Wu JY, Chang JC (2008) Diffusion characteristics and controlled release of bacterial fertilizers from modified calcium alginate capsules.
Bioresour Technol 9: 1904-1910.

24. Cruz MCP, Ravagnani SP, Brogna FMS, Campana SP, Triviño GC, et al. (2004) Evaluation of the diffusion coefficient for controlled release of oxytetracycline from alginate/chitosan/poly (ethylene glycol) microbeads in simulated gastrointestinal environments. Biotechnol Appl Biochem 40: 243-53.

25. Abou El Ela Ael S, Hassan MA, El-Maraghy DA (2014) Ketorolac tromethamine floating beads for oral application: Characterization and in vitro/in vivo evaluation. Saudi Pharm J 22: 349-59. 